\title{
Bile acids and colonic motility in the rabbit and the human
}

\section{Part 1 The rabbit}

\author{
W. O. KIRWAN, A. N. SMITH, W. D. MITCHELL, J. DIANE FALCONER, AND \\ M. A. EASTWOOD
}

From the Department of Clinical Surgery and Wolfson Gastrointestinal Laboratories, Western General Hospital and University of Edinburgh

SUMMARY Colonic motor activity was initiated by infusions of bile salts into the caecum or rectum of the anaesthetized rabbit. Primary bile acids were examined proximally and distally in the colon and elicited marked motor responses. Since dihydroxy bile acids are known to be potent inhibitors of electrolyte and water absorption in the colon, the secondary bile acid deoxycholic acid, the dihydroxy compound most related to cholic acid which is the main bile acid in the rabbit, was examined distally and was also active, but to a lesser extent than cholic acid conjugates in this species. In man, a relationship was found between the faecal bile acid excretion and colonic motility: the introduction of bile acids directly into the human sigmoid colon and rectum also stimulated colonic motility. In man, the dihydroxy compound chenodeoxycholic acid was slightly more active than conjugates of cholic acid.

Reports on the motor action of bile salts on the gastrointestinal tract have been conflicting. Inhibition of the contractility of strips of intestinal smooth muscle has been reported (D'Errico, 1910; Boulet, 1921; Schwartz and Magerl, 1924). In vivo experiments indicate that bile salts may stimulate motility (Horrall, 1938; Haney et al., 1939) and the introduction of bile into the colon and rectum results in defaecation (Hallion and Nepper, 1907; Schüpbach, 1908). However, the purity must nowadays be questioned of bile salt preparations which were formerly precipitated or crystallized from bile with other biliary constituents present as contaminants. Since these were the ones used in the experiments before modern methods of preparation, it was decided to reinvestigate the effect of some bile acids, in the rabbit.

Cholic acid was examined for its action on the proximal colon, since it is the principal primary bile acid present at that site, and also because it is known to have a modest effect on water and electrolyte reabsorption; any motor effect would be more clearly shown to be independent of this action, and attributable to true motor stimulation of the bowel,

Received for publication 18 September 1975. more so if precipitate defaecation or diarrhoea were also produced. In the rabbit, the principal faecal or secondary bile acid is deoxycholic acid, derived from cholic acid and conjugated with glycine. The effects of cholic acid were therefore contrasted with deoxycholate, but the taurocholate conjugate was used more frequently than the glycocholate because of its greater solubility.

\section{Methods}

The animals used were Edinburgh University Bush strain rabbits, 4 to 6 months old, weighing between 2.5 and $3 \mathrm{~kg}$. They were fed on rabbit pellets, were free of disease, and were fasted for a period of 12 hours preceding each experiment.

The bile acid conjugates used were obtained from the Maybridge Chemical Company, Tintagel, Cornwall, and their purity was at least $90 \%$ as measured by gas liquid chromatography.

Three types of animal experiments were performed.

\section{ACUTE EXPERIMENT}

The abdomen was opened under general anaesthesia (nitrous oxide, oxygen, halothane) and the appendix cannulated. A pressure recording tube was passed 
per rectum and motility recorded $15 \mathrm{~cm}$ from the sphincter. Basal motility was recorded for one hour. At the end of this period $50 \mathrm{ml}$ glyco- or tauro-cholic acid, dissolved in distilled water, was infused into the caecum over five minutes. Motility was measured by the method described by Smith et al. (1971) and the results expressed as a motility index. A basal motility index was calculated from the 15 minutes of maximum motility in the 30 minutes before infusion and a post-infusion motility index was calculated from the 15 minutes of maximum motility after infusion. In five acute experiments indigo carmine dye was added to the infused bile acid solution. The animals were killed at the end of the recording period.

In some experiments the rabbits were repeatedly used, thus serving as their own control and minimizing within-subject differences. In this group a Portex intravenous cannula, implanted under general anaesthesia through the rabbit's abdominal wall, was inserted into the appendix which was sutured to the peritoneum of the abdominal wall. The proximal end was buried under the skin. After a two week interval, when the animal had recovered from the operation, infusion experiments were performed by the mere puncture of the skin with a needle. Motility was recorded under general anaesthesia as in the acute experiments. A basal motility index was calculated as described above.

Motility indices were calculated for the four 15 minute periods following the start of infusion. The animals were allowed to recover after each experiment and were used not more than 10 times. Liver function tests were repeated after each experiment. At the end of the series of experiments the histology of the liver, appendix, and colon was examined.

INTRODUCTION OF BILE SALTS INTO THE SIGMOID

The animal was anaesthetized as before and the pressure recording tube passed rectally into the large intestine to $15 \mathrm{~cm}$. Basal motility was recorded and calculated as in the previous experiment. Five millilitres of the test solutions (glyco- or tauro-cholic acid and deoxycholic acid) were infused through the pressure recording tube into the sigmoid at 15 $\mathrm{cm}$. The post-infusion motility was calculated from the 15 minutes of maximum activity during the 30 minutes after infusion.

DETERMINATION OF CHARACTERISTICS OF RABBIT BOWEL CONTENT

The gastrointestinal tract was removed from five fasted rabbits and the quantity, $\mathrm{pH}$, osmolality, and bile acid concentration of its contents measured in order to establish baseline values for the rabbit.

\section{Results}

\section{RABBIT BOWEL CONTENT}

The results are set out in Table 1 .

INTRODUCTION OF BILE SALTS INTO CAECUM 1 Single experiments In five single experiments where indigo carmine dye was added to the infused bile acid the colour was confined to the proximal

\begin{tabular}{|c|c|c|c|c|c|c|c|}
\hline \multicolumn{2}{|l|}{ Weight $(g)$} & \multicolumn{2}{|l|}{$p H$} & \multicolumn{2}{|c|}{ Osmolality $(\mathrm{m} . \mathrm{mol} / \mathrm{kg})$} & \multicolumn{2}{|c|}{ Bile acid concentration $(m M)$} \\
\hline Caecal contents & Ileal contents & Саecum & Ileum & Caecum & Ileum & Caecum & Ileum \\
\hline $93 \cdot 6 \pm 37$ & $2 \cdot 2 \pm 0 \cdot 44$ & $\begin{array}{r}5.88 \\
\pm 0.53\end{array}$ & $\begin{array}{l}8 \cdot 8 \\
\text { (pooled) }\end{array}$ & $466 \pm 74$ & $\begin{array}{l}431 \\
I_{\text {(pooled) }}\end{array}$ & $\begin{array}{r}1.98 \\
\pm 0.61\end{array}$ & $\begin{array}{l}2 \cdot 63 \\
\mid \\
\text { (pooled) }\end{array}$ \\
\hline
\end{tabular}

Table 1 (Part 1) Characteristics of ileal and caecal content of five rabbits (mean $\pm S D)$

\begin{tabular}{|c|c|c|c|c|c|c|}
\hline \multirow[t]{2}{*}{ Conjugated bile acid } & \multirow{2}{*}{$\begin{array}{l}\text { Concentration } \\
(m M)\end{array}$} & \multirow{2}{*}{ (no.) } & \multicolumn{2}{|c|}{ Motility index* } & \multicolumn{2}{|c|}{ Change in $M I$} \\
\hline & & & $\begin{array}{l}\text { Pre-infusion } \\
( \pm S E)\end{array}$ & $\begin{array}{l}\text { Post-infusion } \\
( \pm S E)\end{array}$ & & \\
\hline \multirow[t]{4}{*}{ Sodium taurocholate } & 2 & 4 & $871 \pm 276$ & $1531 \pm 219$ & +650 & $P<0.01$ \\
\hline & 4 & 4 & $433 \pm 151$ & $1211 \pm 394$ & +778 & $P<0.012$ \\
\hline & 8 & 3 & $385 \pm 165$ & $932 \pm 428$ & +547 & $P<0.025$ \\
\hline & 16 & 3 & $195 \pm 193$ & $373 \pm 209$ & +178 & (NS) \\
\hline \multirow{2}{*}{ Sodium glycocholate } & 16 & 3 & $283 \pm 215$ & $484 \pm 124$ & +201 & $\mathbf{P}<0.05$ \\
\hline & 24 & 3 & $186 \pm 73$ & $819 \pm 281$ & +633 & $P<0.025$ \\
\hline Distilled water & & 6 & $867 \pm 230$ & $802 \pm 205$ & -65 & (NS) \\
\hline Sodium chloride & $0.9 \mathrm{~g} / 100 \mathrm{ml}$ & 7 & $100 \pm 38$ & $165 \pm 159$ & +65 & (NS) \\
\hline
\end{tabular}

Table 2 (Part 1) Response to different concentrations of bile acids and control solutions in single experiments

*MI : motility index 
colon at the end of the experiment. This experiment was performed on 34 animals (23 bile acid and 11 control solutions) using solutions of bile acids (sodium taurocholate ( $2 \mathrm{mM}$ to $16 \mathrm{mM}$ ) and sodium glycocholate $(8 \mathrm{mM}$ to $24 \mathrm{mM}))$. It is possible to group the taurine and glycine salts together as their effect was similar in equivalent concentration. The results are set out in Table 2 . All the concentrations of bile acid conjugates infused stimulated colonic motility, whereas water and sodium chloride in the same volume had no such effect. Only in the $8 \mathrm{mM}$ concentration of sodium taurocholate did the motility response fail to reach statistical significance. When the 23 rabbits, of this experiment, were considered as a group. there was a statistically significant difference between the pre-infusion motility index $(501 \pm 100)$ and the post-infusion motility index $(1005 \pm 139)(P<0.005)$. The osmolality of the bile salt in solution was $40 \mathrm{mmol}$. Since the osmolality of the caecal contents (containing bile) was $466 \pm 74$, equivalent concentrations of bile salts but of osmolality of less than 40 and of 466 (increased with $\mathrm{NaCl}$ ), were compared and gave similar responses. The maximum motility response occurred between 30 and 45 minutes after infusion. The relationship between the basal motility and the percentage change in motility after bile acid infusion is plotted on Fig. 1.

2. Repeated experiments The response to control solutions and cholic acid solutions (two each of
$1 \mathrm{mM}, 3 \mathrm{mM}$, and $6 \mathrm{mM}$ sodium glycocholate) in the chronic experiments is illustrated in Fig. 2. Bile acid solutions caused an increase in motility maximal at 30 to 45 minutes, whereas control solutions had a slight inhibitory effect, again maximal at 30 to 45 minutes. There was a statistically significant difference $(P<0.01)$ between the effect of bile acid and control solutions in the 30 to 45 minute period.

As in the single experiment it was established, using dye, that the infused fluid remained confined to the proximal colon and at the end of the tests the histology of the liver, appendix, and caecum was found to be normal. The serum lactic dehydrogenase was unchanged following the repeated anaesthesia (179 I.U./1 before; 134 I.U./1 after); the SGOT also remained unchanged (6 I.U./l before; 6 I.U./l after).

3. Introduction of bile acids into sigmoid colon The colonic motility response after infusion of various concentrations of sodium glycocholate $(1 \mathrm{mM}$ to $30 \mathrm{mM}$ ) and sodium deoxycholate (3mM to $24 \mathrm{mM})$ into the sigmoid colon relates to the concentration of bile acid injected (Fig. 3). The effect for each compound is different, sodium glycocholate being more active in eliciting motility effects. Defaecation resulted from concentrations greater than $15 \mathrm{mM}$. The change in motility occurred within 10 to 15 minutes of the infusion and was therefore much more prompt than with bile salts given into the caecum. Control experiments with water caused no

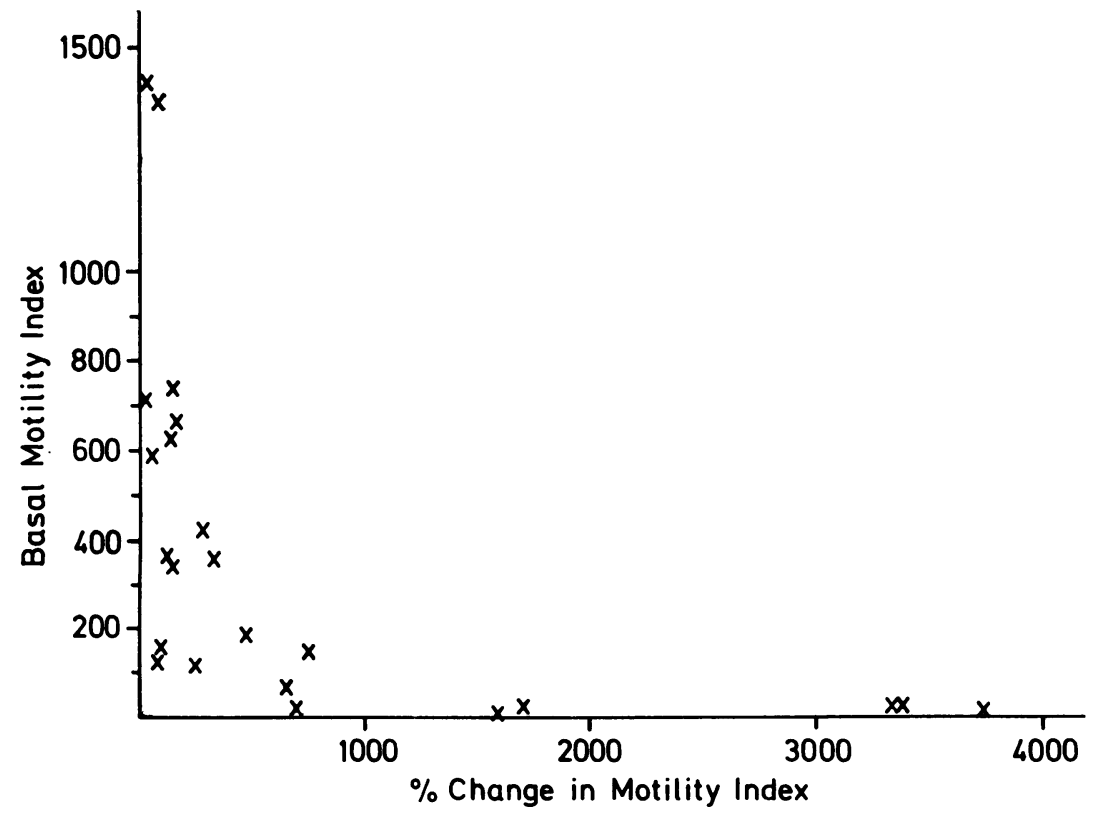

Fig. 1 (Part 1) Exponential relationship between the basal motility and the percentage motility change after $50 \mathrm{ml}$ bile acid (cholic acid) infusion into caecum over five minutes in acute experiments. 


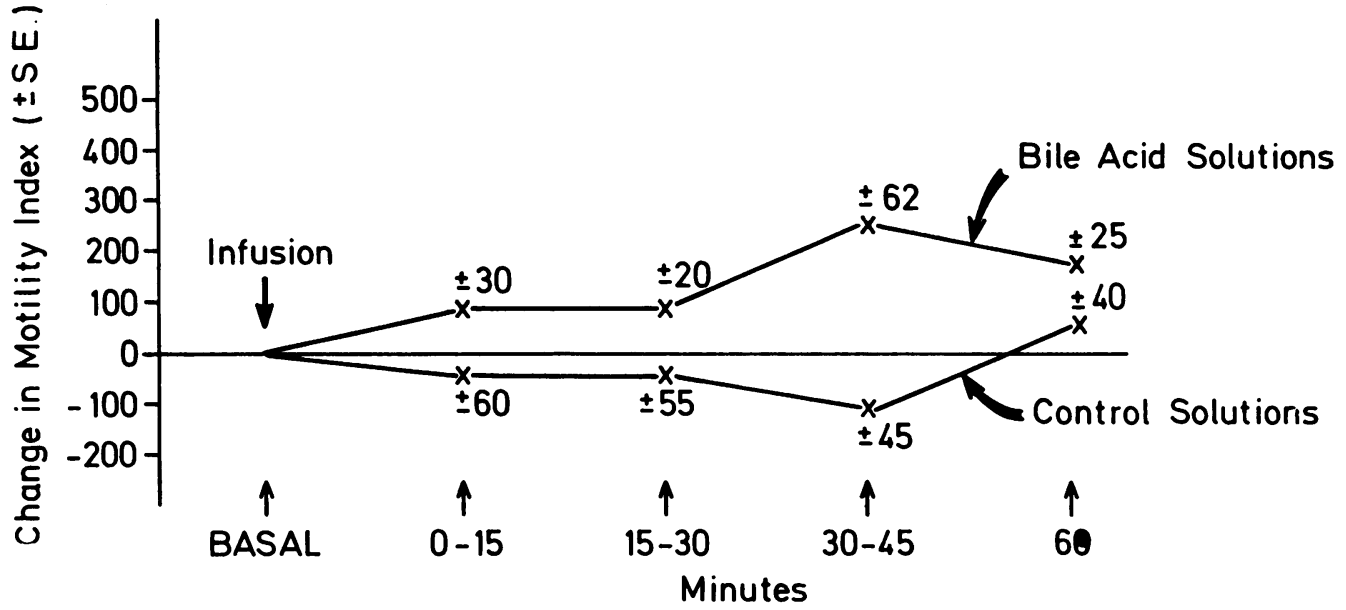

Fig. 2 (Part 1) Increments of motility after bile acid infusion (maximal at 30-45 minutes) and the inhibition of motility by control solutions (again maximal at 30-45 minutes).

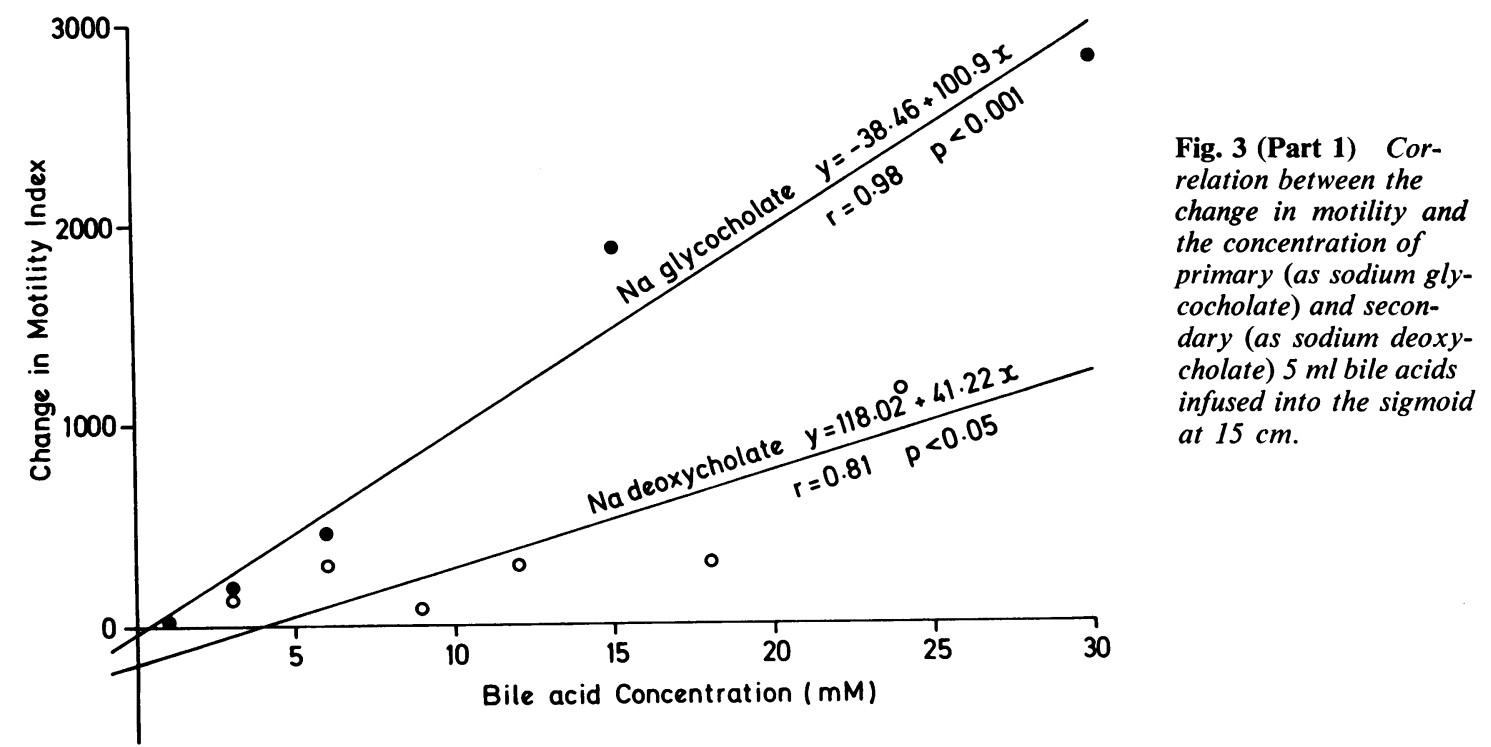

change in motility (before infusion M.I. 625; after infusion M.I. 710).

\section{Discussion}

The bile acid which is the end product of cholesterol catabolism in the rabbit is cholic acid, conjugated with glycine (Haslewood, 1968); there is virtually no chenodeoxycholic acid in these animals. Our studies were therefore confined to cholic acid and the secondary bile acid deoxycholic acid which, in the rabbit, is the principal bile acid present in the faeces. It is known from other animal and human experiments that dihydroxy bile acids-namely, chenodeoxycholic acid and deoxycholic acid-are potent inhibitors of sodium and water reabsorption from the colon (Mekhjian and Phillips, 1970; Mekhjian et al., 1968, 1971); hence their association with watery diarrhoea. But the diarrhoeal effect of bile acids could independently be exerted on the motor function of the gut. It seemed necessary therefore to examine the parent cholic acid since it is 
present in the proximal gut, with modest effects on sodium and water reabsorption; deoxycholic acid was also examined since it is the predominant compound in the distal colon and, as a dihydroxy compound, might be expected to have contrasting actions with cholic acid on salt and water reabsorption. In preliminary experiments, taurocholate behaved as glycocholate so that, despite the inappropriateness to the species, the biologically equivalent taurine salts were used because of greater water solubility leading to greater ease of experimental handling.

Our results show that there was a statistically significant increase in sigmoid colonic motility after the infusion of conjugates of primary bile acids into the caecum $(\mathrm{P}<0.006)$. This motility response was not likely to be due to the infused bile acids advancing directly along the lumen to stimulate the sigmoid directly as dye infusion showed that the bolus remained in the right side of the colon throughout the experiment. Similarly volume alone or osmolality were not responsible: the osmolality of the bile salt solution was $<40 \mathrm{mmol}$ in contrast with distilled water (0) and saline (275); neither of the latter had stimulating effects.

The experiment involving the indwelling cannula was developed to allow repeated experiments and to eliminate inter-animal variation. It is interesting that the maximal response was obtained after the same interval (30 to 45 minutes) as in the single experiment. The control solutions (both saline and water) exerted an inhibitory effect which was most marked at the same time interval as that observed after maximum stimulation by bile acid solutions. The interval before the response is recorded suggests a response beginning in the caecum and propagated distally. The delay in the motility response could also be due to the secondary release by bile acids of intermediary factors which themselves stimulate the colon.

In the acute experiments, there appears to be an exponential relationship between the basal motility and the percentage change in motility in response

\section{Part 2 The human}

Bile flowing down the intestinal tract from the duodenum onwards has been shown to stimulate intestinal motility (Horrall, 1938). The availability of modern synthetic preparations of bile acids renders it possible to compare possible motor actions of primary and secondary bile acids. It is known that chenodeoxycholic acid is principally responsible for the watery diarrhoea of ileal resection to bile acid solutions. Animals with a high basal motility had a poor motility response to the injection of bile acids, while animals with a low basal motility had a high motility response. The possibility exists that the high basal motility found in some animals might be accounted for by the presence in the caecum, before the experiment, of a high concentration of bile acids.

The response of the sigmoid colon to direct contact with bile acids occurred at 10 minutes. In these experiments, there was a high degree of correlation between the response of the sigmoid colon and the concentration of the bile acids instilled, the effect being greater with primary bile acids than secondary ones. Since the secondary ones mainly reside in the distal colon, there would be little spontaneous tendency for motility to be stimulated by bile in the contents of the lumen at this level. But should primary bile acids for any reason predominate, then bile might begin to stimulate the gut via its constituent bile acids. In the rabbit, the dihydroxy compound most appropriate to cholic acid, deoxycholate, was less active than conjugates of this, the main bile acid of the rabbit; whereas in man the dihydroxy compound, chenodeoxycholic acid, has been principally associated with cholerrhoeic enteropathy (Mitchell et al., 1973).

Although there is a dose-response relationship between bile acid concentration and change in the motility index with infusion of bile acids into the sigmoid colon, this relationship was not found after caecal instillation; this suggests a direct effect on the sigmoid colon when locally instilled, but perhaps only an indirect sigmoid motor response when the caecum is perfused. When abnormally high concentrations of bile acids were instilled $(15 \mathrm{mM}$ to $30 \mathrm{mM}$ ), the colon responded with abnormally high motor activity and defaecation resulted.

This study suggests that intraluminal bile acid conjugates can affect colonic motility. For this reason, endogenous and exogenous bile acids were examined for motor activity in humans (Part 2).

(Mitchell et al., 1973). It is not known whether this effect relates to changes in water and salt excretion from the colon or to an alteration of its segmental motor activity.

As in the rabbit experiments (Part 1), the effect of bile acid on motility was studied by a somewhat indirect method.

A group of diarrhoeal patients with enhanced 
faecal bile acid excretion were examined, all of whom had solely primary bile acids in the stoolthat is, chenodeoxycholic and cholic acid (Mitchell and Eastwood, 1972).

A control group of diarrhoeal patients with normal faecal bile acid excretion was also studied; the bile acids in this situation were entirely secondary-that is, deoxycholic and lithocholic acid.

In a further group of patients the primary bile acids, chenodeoxycholic acid and cholic acid, were instilled into the sigmoid colon.

\section{Methods}

Group 1 consisted of seven patients with a daily bile acid excretion in excess of $1000 \mathrm{mg}$. Six of these patients had post-ileal resection and one had postvagotomy diarrhoea. The second group consisted of five patients with a daily faecal bile acid excretion of less than $1000 \mathrm{mg}$. Two of these patients had post-ileal resection diarrhoea, one had Crohn's disease without resection, and two had postvagotomy diarrhoea. Details of group 1 and group 2 patients are shown in Table 1. Group 3 consisted of patients who were referred for routine colonic motility studies as part of their investigation; for undiagnosed abdominal pain, because of the irritable colon syndrome, or diverticular disease. Seven were given taurocholic acid and seven sodium chenodeoxycholic acid in aqueous solution directly into the sigmoid colon. Daily faecal bile acid excretion was not measured in these seven patients.

\section{COLONIC MOTILITY STUDIES}

Colonic motility studies were performed on all patients in groups 1 and 2 during basal, post food and post prostigmine periods (Smith et al., 1971). In the group 3 patients, however, the post food period was omitted and in its place $50 \mathrm{ml}$ of a control solution or a bile acid conjugate solution was infused into the sigmoid at $25 \mathrm{~cm}$ over five minutes and the motility thereafter recorded for $\mathbf{3 0}$ minutes.

The results were expressed as a colonic motility index.

FAECAL BILE ACID ESTIMATION

Stools were collected for a period of at least three days and daily faecal bile acid excretion was determined using the method of Evrard and Janssen (1968) as modified by Mitchell et al. (1973).

\section{Results}

GROUPS 1 AND 2

The basal, post food and post prostigmine motility indices and the daily faecal bile acid and faecal fat results of patients in groups 1 and 2 are shown in

\begin{tabular}{rll}
\hline No. & Name & Clinical details \\
\hline 1 & I. B. & Resection of $60 \mathrm{~cm}$ of terminal ileum for Crohn's disease \\
2 & J. G. & Extensive resection removing multiple coils of terminal ileum and $20 \mathrm{~cm}$ of right colon \\
3 & J. M. & Mesenteric infarct. Resection of $90 \mathrm{~cm}$ of terminal ileum \\
4 & M. B. & Resection of $40 \mathrm{~cm}$ of terminal ileum and $12 \mathrm{~cm}$ of right colon for Crohn's disease \\
5 & T. I. & Resection of $60 \mathrm{~cm}$ of terminal ileum for inflammatory bowel disease of uncertain pathology \\
6 & J. McL. & Resection of $70 \mathrm{~cm}$ of terminal ileum and $25 \mathrm{~cm}$ of colon for Crohn's disease \\
7 & T.S. & Vagotomy and pyloroplasty; post-vagotomy diarrhoea \\
8 & A. McA. & Resection of $75 \mathrm{~cm}$ of terminal ileum for Crohn's disease \\
9 & C. W. & Massive ileal strangulation and resection. Jejuno colic anastomosis \\
10 & A.M. & Vagotomy and pyloroplasty; post vagotomy diarrhoea \\
11 & L.H. & Vagotomy and pyloroplasty; post vagotomy diarrhoea \\
12 & M.P. & Crohn's disease. No resection \\
\hline
\end{tabular}

Table 1 (Part 2) Clinical details of group 1 and 2 patients in present series

\begin{tabular}{|c|c|c|c|c|c|}
\hline \multirow{2}{*}{ Patient } & \multirow{2}{*}{$\begin{array}{l}\text { Bile acids* } \\
\text { (mg/day) }\end{array}$} & \multirow{2}{*}{$\begin{array}{l}\text { Faecal fat } \\
\text { (g/day) }\end{array}$} & \multicolumn{3}{|c|}{ Motility indices } \\
\hline & & & Basal & Post food & Post prostigmine \\
\hline $\begin{array}{l}\text { I. B. } \\
\text { J. G. } \\
\text { J. M. } \\
\text { M. B. } \\
\text { J. McL. } \\
\text { T. I. } \\
\text { T. S. }\end{array}$ & $\begin{array}{l}2876 \\
4251 \\
3340 \\
2091 \\
1675 \\
1158 \\
2310\end{array}$ & $\begin{array}{r}7.9 \\
9.9 \\
10 \cdot 0 \\
28 \cdot 0 \\
26 \cdot 3 \\
7 \cdot 0 \\
5.5\end{array}$ & $\begin{array}{r}1174 \\
573 \\
305 \\
312 \\
1415 \\
-724\end{array}$ & $\begin{array}{r}2405 \\
1917 \\
1349 \\
316 \\
2637 \\
974 \\
648\end{array}$ & $\begin{array}{r}4460 \\
3656 \\
5157 \\
889 \\
4128 \\
3804 \\
2978\end{array}$ \\
\hline Mean $\pm \mathrm{SE}$ & $2528 \pm 972$ & $13.5 \pm 3.6$ & $643 \pm 140$ & $1463 \pm 340$ & $3581 \pm 525$ \\
\hline
\end{tabular}

Table 2 (Part 2) Patients with daily bile acid excretion greater than $1000 \mathrm{mg}$ : colonic motility indices and daily bile acid and fat excretion (group 1)

* Solely primary bile acids 


\begin{tabular}{|c|c|c|c|c|c|}
\hline \multirow{2}{*}{ Patient } & \multirow{2}{*}{$\begin{array}{l}\text { Bile acids* } \\
\text { (mg/day) }\end{array}$} & \multirow{2}{*}{$\begin{array}{l}\text { Faecal fat } \\
\text { (g/day) }\end{array}$} & \multicolumn{3}{|c|}{ Motility indices } \\
\hline & & & Basal & Post food & Post prostigmine \\
\hline $\begin{array}{l}\text { A. McA. } \\
\text { C. W. } \\
\text { A. M. } \\
\text { L. H. } \\
\text { M. P. }\end{array}$ & $\begin{array}{l}572 \\
664 \\
311 \\
723 \\
326\end{array}$ & $\begin{array}{r}2 \cdot 9 \\
13 \cdot 3 \\
18 \cdot 0 \\
7 \cdot 1 \\
0 \cdot 7\end{array}$ & $\begin{array}{l}\overline{397} \\
345 \\
\overline{778}\end{array}$ & $\begin{array}{l}1103 \\
578 \\
114 \\
955 \\
527\end{array}$ & $\begin{array}{r}1831 \\
1796 \\
478 \\
1253 \\
1753\end{array}$ \\
\hline
\end{tabular}

Table 3 (Part 2) Patients with daily bile acid excretion less than $1000 \mathrm{mg}$ : colonic motility indices and daily bile acid and fat excretion (group 2)

*Solely secondary bile acids

Tables 2 and 3 respectively. There was a significantly higher motility index after prostigmine in group 1 (3581 \pm 525$)$ compared with group $2(1442 \pm 262)$ $(P<0.005)$ and to a lesser degree after food $(1463 \pm$ 140, group 1: $655 \pm 178$, group 2, $\mathrm{P}<0.05$ ). Although in the basal period the motility index was higher in group 1, this difference was not statistically significant.

Correlation between bile acid excretion and motility index The regression lines between the daily bile acid excretion and the basal, post food and post prostigmine motility indices are plotted in the
Figure. The correlation was statistically significant in the post prostigmine period $(\mathrm{P}<0.01)$ and in the post food period $(P<0.05)$, but not in the basal period. There was no significant correlation between the faecal fat excretion and colonic motility in any of the three periods.

\section{GROUP 3}

Instillation of bile acids into the sigmoid The results of infusing solutions of differing concentrations of the bile acids, chenodeoxycholic acid and taurocholic acid, into the sigmoid of 14 patients are shown in Table 4. These solutions caused a significant

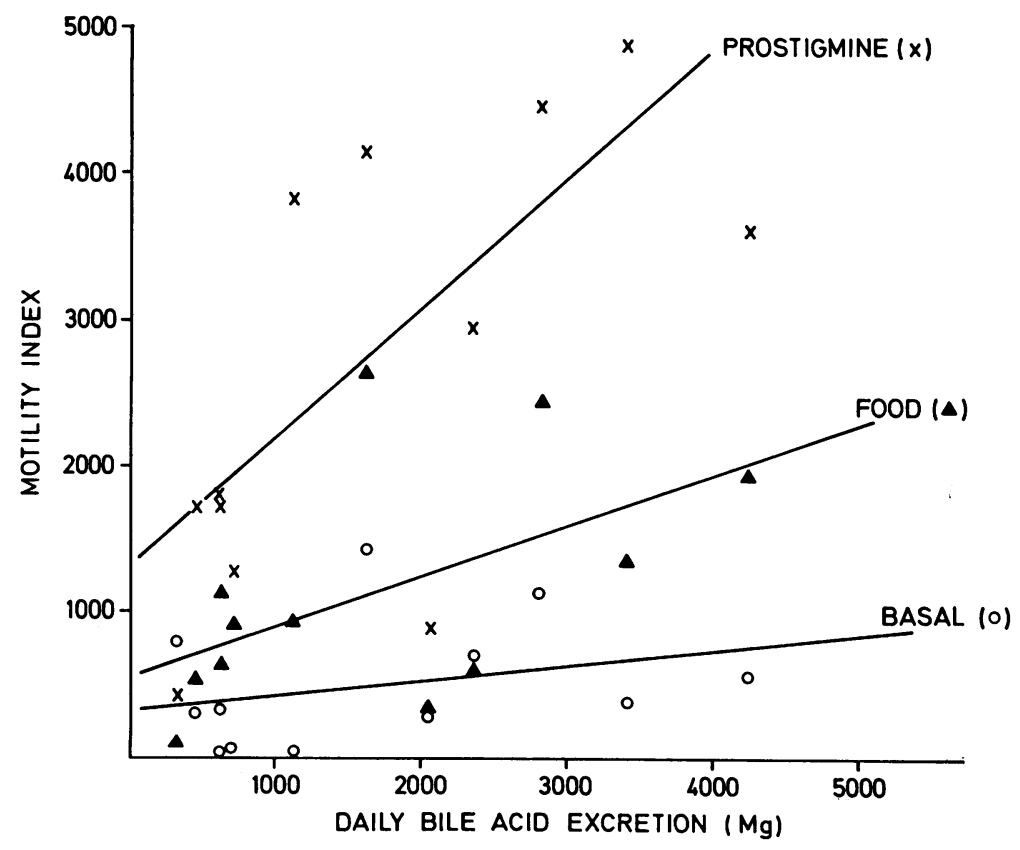

Figure (Part 2) Motility index plotted against daily bile acid excretion.

Prostigmine: $y=1305+0.81 x . \quad n=0.685 . \quad \mathrm{P}<0.01$.

Food : $y=551+0.34 x . \quad n=0.546 . \quad \mathrm{P}<0.05$.

Basal $\quad: y=332+0 \cdot 10 x . \quad n=0 \cdot 301 . \quad(N S)$. 


\begin{tabular}{|c|c|c|c|c|}
\hline \multirow[b]{2}{*}{ Solution } & \multirow{2}{*}{$\begin{array}{l}\text { Osmol. } \\
(m M)\end{array}$} & \multicolumn{2}{|l|}{$M I$} & \multirow[b]{2}{*}{ Change in $M I$} \\
\hline & & Before injection & After injection & \\
\hline $\begin{array}{l}\text { Sod. tauro. chol. } \\
\text { Cheno. deoxy. }\end{array}$ & $\begin{array}{l}2 \cdot 5 \\
2 \cdot 5\end{array}$ & $\begin{array}{l}1030(n=2) \\
820\end{array}$ & $\begin{array}{l}1366(n=2) \\
1266\end{array}$ & $\begin{array}{l}+336 \\
+446^{*}\end{array}$ \\
\hline $\begin{array}{l}\text { Sod. tauro. chol. } \\
\text { Cheno. deoxy. }\end{array}$ & $\begin{array}{l}5 \\
5\end{array}$ & $\begin{array}{l}973(n=2) \\
219(n=2)\end{array}$ & $\begin{array}{l}1274(n=2) \\
1190(n=2)\end{array}$ & $\begin{array}{l}+301 \\
+\quad 971\end{array}$ \\
\hline $\begin{array}{l}\text { Sod. tauro. chol. } \\
\text { Cheno. deoxy. }\end{array}$ & $\begin{array}{l}10 \\
10\end{array}$ & $\begin{array}{l}619 \\
806\end{array}$ & $\begin{array}{l}1581 \\
2014\end{array}$ & $\begin{array}{l}+962 \\
+1208^{*}\end{array}$ \\
\hline $\begin{array}{l}\text { Sod. tauro. chol. } \\
\text { Cheno. deoxy. }\end{array}$ & $\begin{array}{l}15 \\
15\end{array}$ & $\begin{array}{r}619 \\
1003\end{array}$ & $\begin{array}{l}1467 \\
2275\end{array}$ & $\begin{array}{l}+846 \\
+1272\end{array}$ \\
\hline $\begin{array}{l}\text { Sod. tauro. chol. } \\
\text { Cheno. deoxy. }\end{array}$ & $\begin{array}{l}20 \\
20\end{array}$ & $\begin{array}{l}947 \\
259(n=2)\end{array}$ & $\begin{array}{l}1346 \\
845(n=2)\end{array}$ & $\begin{array}{r}+399 \\
+\quad 586\end{array}$ \\
\hline Distilled water & & 677 & 一 & -677 \\
\hline
\end{tabular}

Table 4 (Part 2) Motility response to injection of bile acids into sigmoid

*Estimated from part of record; defaecation produced after five to 10 minutes.

increase in motility for taurocholic acid $(\mathrm{P}<0.0125)$. There was a comparable response in four subjects given chenodeoxycholic acid; diarrhoea was caused in three more subjects so that the experiment in their case was incomplete; yet the motor response estimated for the period studied was excessive (Table 4). The same volume, $50 \mathrm{ml}$ distilled water, caused inhibition of colonic motility and there was no diarrhoea.

\section{Discussion}

Diarrhoea patients with a primary bile acid excretion (group 1 patients) had a significantly greater motility index $(\mathrm{P}<0.005)$ than patients with diarrhoea and secondary bile acid excretion only (group 2 patients). The finding that diarrhoea patients with a high faecal bile acid excretion had a significantly higher colonic motility index in the post food and post prostigmine periods than patients with a much lower faecal bile acid excretion suggests that bile acids may be a factor in the production of this abnormal motility. There was a significant correlation (Figure) between motility caused by food and prostigmine and the daily faecal bile acid excretion. The motor action is further supported by the results obtained when solutions of taurocholic acid and chenodeoxycholic acid were infused into the sigmoid colon (Table 4). In view of these findings, it seems possible that abnormally high quantities of bile acids, mainly primary ones, in the colon cause diarrhoea not only by inhibiting the absorption of water and electrolytes but also by eliciting colonic motor activity.

These observations in the human subject are not exactly the same as in the rabbit experiments (Part 1). Whereas, in the rabbit, bile acids were infused into the caecum, in the human observations we have resorted to measurement of the faecal bile acid content as a means of determining the activity of the compounds present in the colon and passing through it. The association of diarrhoea with a raised motility and raised bile acid excretion, in many instances after an ileal resection, may be a special case and is not necessarily the same as diarrhoea studied by Connell (1962) where the motility index was low. Our second group with diarrhoea had both a low motility index and quantitatively and qualitatively a normal bile acid excretion and these cases are perhaps more akin to those studied by Connell (1962). The bile acids which could be most of all implicated as raising the motility-for example in group 1-were chenodeoxycholic acid and cholic acid. The motor effects found were marginally higher for the dihydroxy bile acid, chenodeoxycholic, than for cholic acid, when these compounds were introduced into the distal bowel, which contrasts with the situation in the rabbit where the most appropriate dihydroxy compound was less active than a cholic acid conjugate.

The motor effect might thus appear to be more related to the primary or secondary status of the bile acid than to the number of hydroxyl groups. The group 1 patients with primary bile acid excretion had a higher motility index than the group 2 patients with secondary bile acids. These two groups differed in other respects. Firstly, the group 1 patients had a higher total bile acid excretion than the group 2 patients, and, secondly, the group 1 patients had solely primary bile acids in their stool, whereas the group 2 patients had solely secondary bile acids. The conclusion that the difference in motility index is related to total bile acid excretion is supported by the finding of a significant correlation between these two variables (Fig. 1; Part 2). The secretory effect of bile acids is related to the number of hydroxyl groups rather than to the division into primary and secondary bile acids, dihydroxy bile acids producing 
the more marked secretory effect. The precise site and mechanism of the motility effect of bile acids however, remains to be elucidated.

This work was done during the tenure of Scottish Hospitals Endowment Research Trust Grant No. 418 , to Mr. A. N. Smith. We are indebted to Miss E. G. P. Drummond for skilled technical assistance.

\section{References}

Boulet, L. (1921). Influence de la bile humaine sur la motricité de l'intestin humain. Comptes Rendus des Séances de la Société de Biologie, 84, 395-396.

Connell, A. M. (1962). The motility of the pelvic colon. Part II-Paradoxical motility in diarrhoea and constipation. Gut, 3, 342-348.

D'Errico, G. (1910). Wirkung der Galle und der gallensauren Salze auf den Tonus und die autonatischen Bewegungen des Darmohrs. Zeitschrift für Biologie, 54, 286-298.

Evrard, E., and Janssen, G. (1968). Gas liquid chromatographic determination of human faecal bile acids. Journal of Lipid Research, 9, 226-236.

Hallion, L., and Nepper, H. (1907). Influence excitomotrice de la bile sur l'intestin. 1: Action sur le rectum. Comptes Rendus des Séances de la Société de Biologie, 64, 182-184.

Haney, H. F., Roley, W. C., and Cole, P. A. (1939). The effect of bile on the propulsive motility of Thiry Vella loops in dogs. American Journal of Physiology, 126, 82-88.

Haslewood, G. A. D. (1968). Evolution and bile salts. In Handbook of Physiology. Section 6, vol. 5, pp. 2375-2390. American Physiological Society: Washington D.C.

Horrall, O. H. (1938). Bile: Its Toxicity and Relation to Disease. University of Chicago Press: Chicago.

Mekhjian, H. S., and Phillips, S. F. (1970). Perfusion of the canine colon with unconjugated bile acids. Gastroenterology, 59, 120-129.

Mekhjian, H. S., Phillips, S. F., and Hofmann, A. F. (1968). Conjugated bile salts block water and electrolyte transport by the human colon. (Abstr.). Gastroenterology, 54, 1256.

Mekhjian, H. S., Phillips, S. F., andHofmann, A. F. (1971). Colonic secretion of water and electrolytes induced by bile acids: perfusion studies in man. Journal of Clinical Investigation, 50, 1569-1577.

Mitchell, W. D., and Eastwood, M. A. (1972). Faecal bile acids and neutral steroids in patients with ileal dysfunction. Scandinavian Journal of Gastroenterology, 7, 29-32.

Mitchell, W. D., Findlay, J. M., Prescott, R. J., Eastwood, M. A., and Horn, D. B. (1973). Bile acids in the diarrhoea of ileal resection. Gut, 14, 348-353.

Schüpbach, A. (1908). Über den Einfluss der Galle auf die Bewegung des Dünndarnes. Zeitschrift für Biologie, 51, $1-41$.

Schwartz, C., and Magerl, C. (1924). Beiträge zur Physiologie der Verdauung: 7. Über den Einfluss von Galle und Zucker auf den Tonus und die Pendelbeuregungen des überlebenden Katzendarmes. Pflügers Archiv für die gesammte Physiologie des Menschen und der Tiere, 202, 509-522.

Smith, A. N., Giannakos, V., and Clarke, S. (1971). Late results of colomyotomy. Journal of the Royal College of Surgeons of Edinburgh, 16, 276-286. 